\title{
El problema del pasado es que no pasa ${ }^{1}$
}

Boaventura de Sousa Santos

Este año se conmemora el centenario de la Revolución Rusa - me refiero exclusivamente a la Revolución de Octubre, la que sacudió el mundo y condicionó la vida de cerca de un tercio de la población mundial en las décadas siguientes - y también se conmemoran los 150 años de la publicación del primer volumen de El capital de Karl Marx. Juntar ambas efemérides puede parecer extraño, porque Marx nunca escribió con detalle sobre la revolución y la sociedad comunista y, de haberlo hecho, resulta inimaginable que lo que escribiese tuviera cierto parecido con lo que fue la Unión Soviética (URSS), sobre todo después de que Stalin asumiera la dirección del partido y del Estado. La verdad es que muchos de los debates que la obra de Marx suscitó durante el siglo $\mathrm{XX}$, fuera de la URSS, fueron una forma indirecta de discutir los méritos y deméritos de la Revolución Rusa.

Ahora que las revoluciones hechas en nombre del marxismo terminaron o evolucionaron hacia... el capitalismo, tal vez Marx (y el marxismo) tenga por fin la oportunidad de ser discutido como merece, como teoría social. La verdad es que el libro de Marx, que tardó cinco años en vender sus primeros mil ejemplares antes de convertirse en uno de los libros más influyentes del siglo XX, ha vuelto a convertirse en un bestseller en los últimos tiempos $\mathrm{y}$, dos décadas después de la caída del Muro de Berlín, al fin estaba siendo leído en países que habían formado parte de la URSS.

1 Traducción de Antoni Aguiló y José Luis Exeni Rodríguez. Texto originalmente publicado en el sitio de Página 12, en 09 de febrero de 2017. Disponible en: <https://www.pagina12.com.ar/19067-el-problema-del-pasado-es-que-nopasa>. Acceso en: 20 oct. 2017.

\section{$\overline{\text { Boaventura de Sousa Santos }}$}

Professor da Universidade de Coimbra e da Universidade de Wisconsin-Madison E-mail: bsantos@ces.uc.pt. 
¿Qué atracción puede suscitar un libro tan denso? ¿Qué reclamo puede tener en un momento en que tanto la opinión pública como la abrumadora mayoría de los intelectuales están convencidos de que el capitalismo no tiene fin y que, en caso de tenerlo, ciertamente no será sucedido por el socialismo?

Muy probablemente, los debates que a lo largo de este año se lleven a cabo sobre la Revolución Rusa repetirán todo lo que ya se ha dicho y debatido y terminarán con la misma sensación de que es imposible un consenso sobre si la Revolución Rusa fue un éxito o un fracaso. A primera vista, resulta extraño, pues tanto si se considera que la Revolución terminó con la llegada de Stalin al poder (la posición de Trotsky, uno de los líderes de la revolución) como con el golpe de Estado de Boris Yeltsin en 1993, parece cierto que fracasó. Sin embargo, esto no es evidente, y la razón no está en la evaluación del pasado, sino en la evaluación de nuestro presente. El triunfo de la Revolución Rusa consiste en haber planteado todos los problemas a los que las sociedades capitalistas se enfrentan hoy. Su fracaso radica en no haber resuelto ninguno. Excepto uno. En otros textos pienso abordar algunos de los problemas que la Revolución Rusa no resolvió y siguen reclamando nuestra atención. Aquí me voy a concentrar en el único problema que resolvió.

¿Puede el capitalismo promover el bienestar de las grandes mayorías sin que esté en el terreno de la lucha social una alternativa creíble e inequívoca al capitalismo? Este fue el problema de que la Revolución Rusa resolvió, y la respuesta es no. La Revolución Rusa mostró a las clases trabajadoras de todo el mundo, y muy especialmente a las europeas, que el capitalismo no era una fatalidad, que había una alternativa a la miseria, a la inseguridad del desempleo inminente, a la prepotência de los patrones, a los gobiernos que servían a los intereses de las minorías poderosas, incluso cuando decían lo contrario. Pero la Revolución Rusa ocurrió en uno de los países más atrasados de Europa y Lenin era plenamente consciente de que el éxito de la revolución socialista mundial y de la propia Revolución Rusa dependía de su extensión a los países más desarrollados, con sólida base industrial y amplias clases trabajadoras. En aquel momento, ese país era Alemania. 
El fracaso de la revolución alemana de 19181919 hizo que el movimiento obrero se dividiera y buena parte de él pasase a defender que era posible alcanzar los mismos objetivos por vías diferentes a las seguidas por los trabajadores rusos. Pero la idea de la posibilidad de una sociedad alternativa a la sociedad capitalista se mantuvo intacta. Se consolidó, así, lo que pasó a llamarse reformismo, el camino gradual y democrático hacia una sociedad socialista que combinase las conquistas sociales de la Revolución Rusa con las conquistas políticas y democráticas de los países occidentales. En la posguerra, el reformismo dio origen a la socialdemocracia europea, un sistema político que combinaba altos niveles de productividad con altos niveles de protección social. Fue entonces que las clases trabajadoras pudieron, por primera vez en la historia, planear su vida y el futuro de sus hijos. Educación, salud y seguridad social públicas, entre muchos otros derechos sociales y laborales. Quedó claro que la socialdemocracia nunca caminaría hacia una sociedad socialista, pero parecía garantizar el fin irreversible del capitalismo salvaje y su sustitución por un capitalismo de rostro humano.

Entretanto, del otro lado de la "cortina de hierro", la República Soviética (URSS), pese al terror de Stalin, o precisamente por su causa, revelaba una pujanza industrial portentosa que transformó en pocas décadas una de las regiones más atrasadas de Europa en una potencia industrial que rivalizaba con el capitalismo occidental y, muy especialmente, con Estados Unidos, el país que emergió de la Segunda Guerra Mundial como el más poderoso del mundo. Esta rivalidad se tradujo en la Guerra Fría, que dominó la política internacional en las siguientes décadas. Fue ella la que determinó el perdón, en 1953, de buena parte de la inmensa deuda de Alemania occidental contraída en las dos guerras que infligió a Europa y que perdió.

Era necesario conceder al capitalismo alemán occidental condiciones para rivalizar con el desarrollo de Alemania oriental, por entonces la república soviética más desarrollada. Las divisiones entre los partidos que se reclamaban defensores de los intereses de los trabajadores (los partidos socialistas o socialdemócratas y los partidos comunistas) fueron parte importante de la Guerra Fría, 
con los socialistas atacando a los comunistas por ser conniventes con los crímenes de Stalin y defender la dictadura soviética, y con los comunistas atacando a los socialistas por haber traicionado la causa socialista y ser partidos de derecha muchas veces al servicio del imperialismo norteamericano. Poco podían imaginar en ese momento lo mucho que los unía.

Mientras tanto, el Muro de Berlín cayó en 1989 y poco después colapsó la URSS. Era el fin del socialismo, el fin de una alternativa clara al capitalismo, celebrado de manera incondicional y desprevenida por todos los demócratas del mundo. Al mismo tiempo, para sorpresa de muchos, se consolidaba globalmente la versión más antisocial del capitalismo del siglo XX, el neoliberalismo, progresivamente articulado (sobre todo a partir de la presidencia de Bill Clinton) con la dimensión más depredadora de la acumulación capitalista: el capital financiero. Se intensificaba, así, la guerra contra los derechos económicos y sociales, los incrementos de productividad se desligaban de las mejoras salariales, el desempleo retornaba como el fantasma de siempre, la concentración de la riqueza aumentaba exponencialmente. Era la guerra contra la socialdemocracia, que en Europa pasó a ser liderada por la Comisión Europea, bajo el liderazgo de Durão Barroso, y por el Banco Central Europeo.

Los últimos años mostraron que, con la caída del Muro de Berlín, no colapsó solamente el socialismo, sino también la socialdemocracia. Quedó claro que las conquistas de las clases trabajadoras en las décadas anteriores habían sido posibles porque la URSS y la alternativa al capitalismo existían. Constituían una profunda amenaza al capitalismo y éste, por instinto de supervivencia, hizo las concesiones necesarias (tributación, regulación social) para poder garantizar su reproducción. Cuando la alternativa colapsó $\mathrm{y}$, con ella, la amenaza, el capitalismo dejó de temer enemigos y volvió a su voracidad depredadora, concentradora de riqueza, rehén de su contradictoria pulsión para, en momentos sucesivos, crear inmensa riqueza y luego después destruir inmensa riqueza, especialmente humana.

Desde la caída del Muro de Berlín estamos en un tiempo que tiene algunas semejanzas con el período de la Santa Alianza que, a 
partir de 1815 y tras la derrota de Napoleón, pretendió barrer de la imaginación de los europeos todas las conquistas de la Revolución Francesa. No por coincidencia, y salvadas las debidas proporciones (las conquistas de las clases trabajadoras que todavía no fue posible eliminar por vía democrática), la acumulación capitalista asume hoy una agresividad que recuerda al periodo pre Revolución Rusa. Y todo lleva a creer que, mientras no surja una alternativa creíble al capitalismo, la situación de los trabajadores, de los pobres, de los emigrantes, de los jubilados, de las clases medias siempre al borde de la caída abrupta en la pobreza no mejorará de manera significativa. Obviamente que la alternativa no será (no sería bueno que fuese) del tipo de la creada por la Revolución Rusa. Pero tendrá que ser una alternativa clara. Mostrar esto fue el gran mérito de la Revolución Rusa. 